\title{
Perception and utilization of complementary and alternative medicine (CAM) among University of Sharjah (UOS) students
}

\author{
Osama Mohamed Ibrahim ${ }^{1,2}$, Mohamed E. A. Rashrash ${ }^{3}$ Sameh Soliman ${ }^{4}$
}

Original Article

\author{
'Pharmacy Practice and Pharmacotherapeutics Department, College of Pharmacy, University \\ of Sharjah, UAE \\ ${ }^{2}$ Department of Clinical Pharmacy, Faculty of Pharmacy, Cairo University, Egypt. \\ ${ }^{3}$ University of Charleston, School of Pharmacy, USA. \\ ${ }^{4}$ Department of Medicinal Chemistry, College of Pharmacy, University of Sharjah, UAE.
}

\begin{abstract}
Background: Complementary and Alternative Medicine (CAM) is a term used for practices and use of products other than conventional standard evidence-based medical care.

Objective: To assess the CAM knowledge and utilization among University of Sharjah students, UAE.

Method: A cross-sectional survey study was conducted. 250 surveys among UOS students were distributed. The data was obtained through a well-designed questionnaire of 3 main categories. The first part was designed to collect socio-demographic data, while the second part mainly measured CAM knowledge and the practicing pattern. The last section was developed to assess CAM beliefs and psychological behavior behind CAM utilization.

Results: 214 participants agreed to participate (response rate 85.6\%), and 81\% reported their belief in CAM as medical therapy. The reason behind their belief in CAM was due to efficacy (37\%) and safety (21\%). Approximately $74 \%$ of participants claimed their CAM knowledge, and the most frequently used CAM therapy was cupping. Most participants (47\%) gained their knowledge from regular courses offered by UOS. Around 33\% of the participants consult their physicians before utilizing CAM therapy. However, $42 \%$ utilized CAM by unlicensed practitioners.

Conclusion: Obtained results indicated the high level of CAM knowledge among UOS students in particular females while cupping being the most frequent used CAM therapy. The main reasons justifying the use of cupping was religion, and cultural-based. The lack of sufficient scientific data and the minimal link between the physician and the consumers were the main obstacles attributed to the limited use of CAM.
\end{abstract}

Received: 05 February 2019, Accepted: 26 June 2019

Key Words: CAM, perception, sharjah, students, survey.

Corresponding Author: Ibrahim, Osama Mohamed, PhD, IPharmacy Practice and Pharmacotherapeutics Department, College of Pharmacy, University of Sharjah, UAE, Tel.: +971 501667203, E-mail: oibrahim@sharjah.ac.ae.

Bulletin of Faculty of Pharmacy, Cairo University, ISSN: 1110-0931, Vol. 57, No. 1

\section{INTRODUCTION}

Complementary and alternative medicine (CAM) is a term used for practicing medical products that are not considered as a part of the conventional standard evidencebased medical care. CAM lack scientific evidence on their efficacy and safety ${ }^{[1]}$. According to the National Centre for Complementary and Integrative Health $(\mathrm{NCCIH}), \mathrm{CAM}$ is used either as complementary medicine along with conventional medicine or as an alternative instead of the conventional medicine ${ }^{[2]}$. CAM consists of a diverse group of medical practices, which revolves around using energy power or natural products for healing instead of using the science-based practices and medications ${ }^{[2,3]}$.

The use of CAM started on the 1970s and referred to as "irregular" which changed later on to "alternative". CAM practitioners promoted the "freedom of choice" as a way to remove the quackery perception ${ }^{[4]}$. The general objective of medicine is to mark the reason behind the disease and aid in healing. This discipline has progressed over millennia from ancients due to religious beliefs, and social thoughts and traditional medicine included diverse approaches and beliefs incorporating plants, exercise, and spiritual therapy. History of CAM has links with numerous cultures and practices that were considered as conventional medicine at their time. The origin of CAM goes back as 5000 years ago, and one of the oldest forms is Chinese traditional medicine (CTM) which is based on restoring the balance of the body by using herbal medicine, acupuncture. A large number of complementary medicines were generated from ancient Egyptians ${ }^{[5]}$ including in particular cupping ${ }^{[6]}$. Up to date cupping is used to prevent some diseases, and at the present time, many studies are trying to clarify the clinical efficacy of cupping and its impact on improving quality of life ${ }^{[6]}$. 
Even though CAM lacks scientific support, it is becoming even more popular with time for many reasons including the persuasion of media, friends, and relatives, or from previous experiences ${ }^{[7-12]}$, results in many consumers believe that CAM is effective $\mathrm{e}^{[7]}$ and safe ${ }^{[13]}$ type of medical therapy. CAM providers deliver misguiding to the patients when the conventional healthcare is not effective ${ }^{[7]}$. Unfortunately, the misuse of CAM as complementary medicine might not only result in financial loss, but it can result in a reduction of its effectiveness ${ }^{[7]}$. As such, CAM is not taught as part of science-based programs in medical schools. However, many countries are moving toward the adaptation of CAM in their medical curriculum ${ }^{[14]}$. Regardless of how CAM popularity might be related to fraud, it is a fact that some practices included in CAM existed for numerous years while science-based medicine was originated. As a result, the attention of WHO was gained to implant the first Traditional Medicine Strategy. The released strategies/ guidelines aim to rationalize CAM utilization to guarantee patients' wellbeing. WHO keeps updating and stating new regulations to ensure the safe and effective consumption/ practice of CAM. However, these guidelines increased the confidence of some healthcare practitioners to recommend and even practice $\mathrm{CAM}^{[15]}$.

\section{$U A E$ policies and regulations of CAM practices}

To ensure and control, CAM utilization in UAE, Health Authority Abu Dhabi (HAAD) developed rules for the different types of approved practices in the country[16].

Table 1: Minimum qualification requirements for CAM licensing in UAE, for example acupuncture practitioner ${ }^{[16]}$.

\begin{tabular}{|c|c|c|}
\hline Title & Qualifications & Experience \\
\hline \multirow{4}{*}{$\begin{array}{l}\text { Acupuncture } \\
\text { Practitioner }\end{array}$} & $\begin{array}{l}\text { Bachelor of science at } \\
\text { least five years of which } \\
\text { including a training } \\
\text { programme }\end{array}$ & $\begin{array}{l}\text { Minimum required } \\
\text { experience is two years } \\
\text { following the training. }\end{array}$ \\
\hline & $\begin{array}{l}\text { A minimum of two years, } \\
\text { full time authorized } \\
\text { acupuncture } \\
\text { course, }\end{array}$ & \multirow[b]{2}{*}{$\begin{array}{l}\text { Minimum required } \\
\text { experience is three years } \\
\text { following the training. }\end{array}$} \\
\hline & $\begin{array}{l}\text { or a part-time equal } \\
\text { to } 2500 \text { hour with } \\
\text { certification from national } \\
\text { certificate commission of } \\
\text { acupuncture and oriental } \\
\text { medicine (NCCAOM) or } \\
\text { its equivalent. }\end{array}$ & \\
\hline & $\begin{array}{l}\text { The physician is carrying } \\
\text { a license to practice } \\
\text { acupuncture and holding } \\
\text { an authorized training } \\
\text { certificate (at least } 800 \mathrm{hrs,} \\
\text { which is equivalent to the } \\
\text { one-year course). }\end{array}$ & Not required. \\
\hline
\end{tabular}

\section{Factors affecting CAM utilization}

Most people utilizing CAM are usually educated, married young women and with high income and concerns about their health ${ }^{[15,17]}$. Moreover, people with chronic conditions such as diabetes, cardiovascular and cancer ${ }^{[18]}$ are more likely using CAM. Religion, culture, and environment also are important factors that impact the type of CAM practice within a certain population, for example, a study conducted in KSA shows that many Saudi citizens are practicing cupping due to a religion believe since it is recommended by Prophet Mohammed ${ }^{[19]}$. Other studies elucidate that Chinese people are practicing acupuncture, as it's part of their ancestor's traditions ${ }^{[20]}$.

\section{Experminental design and methodology}

\section{Study design}

A cross-sectional survey study was conducted to measure the awareness and pattern of CAM utilization among UOS students. Using Roasoft online sample size calculator and targeting 5\% margin of error with level of confidence of $95 \%$ with expected response rate of $85 \%$, the calculated sample size to obtain a power of $80 \%$ was 193. Accordingly, 250 surveys were randomly distributed across the University. The distribution of the questionnaire was done through personal interview. The research assistant of the study who have been trained and previously performed this type of interview and data collection was responsible for making the interview and collecting the filled questionnaire.

\section{Study population}

The surveys in both Arabic and English languages were randomly distributed across the University including both medical/non-medical colleges. The surveys were distributed randomly to students present in the cafeteria, classes, and library and during Universities events/ conferences. Furthermore, the surveys were included both genders, local and non-local, Arab and non-Arab. Additionally, an online survey was distributed through a dedicated website.

\section{Ethical approval}

Ethical approval for this study was obtained from the University of Sharjah research ethics committee (REC18-02-22-01-S). Respondents' agreed on joining the study by either signing a consent form of approval or by clicking agree on the icon on the web form. The complete confidentiality of the participants was preserved, and personal information was not provided.

\section{Questionnaire}

A questionnaire of 17 questions was divided into three sections. The first section contained six items and designed to collect socio-demographic data, while the second part included eight questions, which mainly measured CAM knowledge and pattern of practice. The last section presented in 3 items were developed to assess CAM believes and psychological behavior is regarding the use of CAM. The questions of the questionnaire were compiled from different articles and were then adjusted and modified. The validity of the questioner questions was measure by calculating the Cronbach alpha test and it was 0.73 . 


\section{Statistical Analysis}

A descriptive analysis was performed by using SPSS Version 20, and the collected data were presented in the form of chart/graphs using Excel. Chi-square test was used to check the correlation between variables where P-value of less than 0.05 was considered as statistically significant.

\section{RESULTS}

A survey study conducted on undergraduate students at the University of Sharjah, UAE. Out of the 250 participants approached to fill the survey, only 214 agreed to participate (Response rate $=85.6 \%)$. The average age of participants in this study was 21.6 years $(\mathrm{SD}=2.3)$. The age range from 18 to 25 years. Around $81 \%(n=173)$ of the participants were Arabs, while 11\% $(\mathrm{n}=25)$ were non- Arabs and 6\% $(n=12)$ were locals (Table 2). In terms of participants' gender, 69\% ( $\mathrm{n}=148)$ were females, and 31\% (66) were males. On the other hand, 59\% $(n=126)$ were enrolled in medical colleges representing $72 \%(n=94)$ at the college of pharmacy, $9 \%(n=12)$ at the college of medicine, $6 \%(n=8)$ at the college of dentistry and $13 \%(n=16)$ at the college of health sciences; around $37 \%(\mathrm{n}=79)$ were seniors students, while $30 \%(n=64)$ were second or third year students, and $15 \%(\mathrm{n}=32)$ were freshmen students (Table 2$)$.

Table 2: Population demography

\begin{tabular}{cccc}
\hline $\begin{array}{c}\text { Patients' Demographics } \\
(\mathrm{n}=214)\end{array}$ & Items & $\mathrm{n}$ & Percentage \\
\hline \multirow{3}{*}{ Ethnicity } & Arab & 173 & $80.8 \%$ \\
& Non-Arabs & 25 & $11.7 \%$ \\
& Locals & 16 & $7.5 \%$ \\
Gender & Female & 148 & $69.1 \%$ \\
& Male & 66 & $30.9 \%$ \\
Educational background & Medical & 126 & $58.9 \%$ \\
& Non-Medical & 88 & $41.1 \%$ \\
& First year & 32 & $14.95 \%$ \\
& Second/Third year & 64 & $29.9 \%$ \\
Year of study & Fourth year & 20 & $9.33 \%$ \\
& Seniors & 82 & $38.34 \%$ \\
& Postgraduate & 16 & $7.48 \%$ \\
\hline
\end{tabular}

\section{CAM Perception/knowledge among UOS students}

The survey showed that most of the respondents $74 \%$ $(n=158)$ were aware of CAM; where $46 \%(n=99)$ have studied CAM through a special course at their colleges, $23 \%(n=50)$ know CAM through advertisements and/ or family/friends, and only $7 \%$ of the participants know CAM through specialized CAM centers across UAE.

\section{CAM popularity and utilization among UOS students}

Most familiar types of CAM known between participants were cupping and acupuncture, representing $77 \% \quad(n=164)$ and $72 \% \quad(n=154)$ respectively; while massage therapy, naturopathy and reflexology represented $65 \%(\mathrm{n}=140), 53 \%(\mathrm{n}=114)$ and $46 \%(\mathrm{n}=99)$, respectively. Other known CAM practices were represented as $42 \%$ $(n=89)$ for homeopathy, 35\% $(n=75)$ for chiropractic, $29 \%(n=62)$ for, self- care CAM, $27 \%(n=57)$ for TCM, $22 \%(n=47)$ for Ayurveda, $18 \%(n=38)$ for Reiki, and 9\% $(n=20)$ for therapeutic touch.

A Chi-square analysis was conducted to assess the correlation between the knowledge of CAM and the participant's medical background where analysis indicated a statistically significant association between the two factors $(P<0.05)$. On the other hand, there was no correlation between ethnicity and knowledge of CAM $(P>0.05)$. Furthermore, cupping was the predominant type of CAM utilized between participants with $49 \%(n=104)$, indicating that religious background was significantly affecting the use of CAM in Sharjah, UAE.

The obtained data also showed a strong correlation between being female students and CAM knowledge $(P \leq 0.041)$.

On the other hand, utilization of other CAM therapy was represented as massage therapy $(28 \%, \mathrm{n}=60)$, naturopathy $(19 \%, n=41)$, acupuncture $(15 \%, n=33)$, reflexology $(11 \%$, $\mathrm{n}=23)$, chiropractic $(9 \%, \mathrm{n}=19)$ and around $6 \%(\mathrm{n}=13)$ utilized homeopathy.

The involvement of physicians in decision-making utilization of CAM was assessed by asking the participants directly. Only $33 \%$ asked their physicians before practicing CAM, while 57\% did not, and 10\% claimed that they did not seek medical advice, but they informed their physicians later.

\section{Pattern use of CAM among UOS students}

It was shown that the highest percentage $34 \%$ of participants utilized CAM only once during their lifetime, while those practiced CAM regularly every year and every couple of years were representing $20 \%$ and $30 \%$, respectively; and those using CAM every month and every other month were $7 \%$ and $10 \%$, respectively.

The place of CAM utilization was assessed, and the data revealed that $38 \%$ of the participants practiced CAM at home by a relative person, while around $28 \%$ were applied CAM in a licensed center in the UAE, and $18 \%$ considered hospitals as their preferred place to use CAM. On the other hand, a small percentage representing 12\% were applied CAM oversees, and 4\% applied CAM at unlicensed centers.

\section{The reasoning of CAM utilization among UOS students}

It was shown that the majority $81 \%$ of the respondents were strongly trusted in CAM usage, while the minority $19 \%$ were not. The reasons for using CAM were due to the participants believe in CAM effectiveness $39 \%$, while $26 \%$ thought that CAM has less side effect, $20 \%$ showed religious-based reasons and 15\% were due to holistic and health beliefs. On the other hand, the main reason for those $64 \%$ did not believe in CAM was due to the lack of sufficient scientific data. However, $17 \%$ was against the use of CAM due to disbelieving in its efficacy, while the 
rest $19 \%$ was due to economic reason in particular that health insurance does not cover CAM use.

\section{DISCUSSION}

Over the past decade, the global popularity of CAM has seen a considerable development; this development included the Arab-world as well. The number of scientific researches and investigations on CAM therapy published between 1980-1989 are counted to 29 publications from the Arab world, and this number was increased to 66 publications in $2013^{[21]}$. Furthermore, the attitude of the governments towards CAM also promoted, since the health authorities in the United Arab Emirates set rules to regulate the CAM practices and to license the competent practitioners ${ }^{[16]}$

This survey study was conducted to assess the knowledge, pattern of use, and believes of CAM among UOS students at Sharjah, UAE. The survey included 214 participants of both genders and different ethnic groups. The majority of the respondents were Arab students aged between 18 and 25 years old from either medical or nonmedical schools. To our knowledge, this is the first report on the knowledge and utilization of CAM at Sharjah, UAE. The obtained data showed a strong correlation between being female students and CAM knowledge $(P \leq 0.041)$ which is coincident with the data reported in $\mathrm{KSA}^{[22]}$, and Turkey ${ }^{[23]}$.

Furthermore, the results showed a strong correlation between CAM knowledge and medical students when compared to those of the same age and with non- medical background. Similar to previous findings, participants with higher education level including postgraduate students were more CAM knowledgeable ${ }^{[23,24]}$.

Contrary to the data obtained in this survey study, $85.7 \%$ in Ghana showed lack of CAM knowledge ${ }^{[25]}$. While most of the CAM knowledge acquired by UOS students were via regular courses offered at the college level at UOS, most knowledge obtained in Ghana were via advertisements ${ }^{[26]}$. Cupping, acupuncture, massage were the most popular types of CAM among UOS students, while other types of CAM that depend on holistic philosophy including Reiki and therapeutic touch were very low ${ }^{[27]}$. This can be explained by the low exposure to these types of therapy and the cultural and religious background of the participants. It is noticeable that knowledge of CAM differs from one study to another depending on the availability of therapy in certain community/environment. For instance, a study carried in Malaysia ${ }^{[28]}$ the knowledge of faith therapy was prevalence, while Ayurveda was most popular in a Swedish study ${ }^{[29]}$.

Moreover, cupping practicing represented the highest percentage (49\%) among respondents, which confirmed by a strong positive correlation $(P \leq 0.029)$ with a religious background. The reason behind this could be explained by the location of the study was conducted in a more conservative place, Sharjah; where most population follow the Sunnah of Prophet Mohammed where cupping was reported during his period.

Seeking health professional advice for CAM use is a plus in particular in case of chronic diseases. Unfortunately, our study showed that a significant percentage $(57 \%)$ of participants were using CAM without physicians' advice Which is coincident a study conducted in Ajman, where most of the respondents utilize CAM without medical advice $^{[30]}$. Despite the fact that Dubai health authority DHA set many regulations to control CAM use and practice in UAE, utilizing CAM at home by the unlicensed practitioner is prevalence $(38 \%)$ in our study. Indicating the unawareness of the adverse consequences associated with some practices such as the infection may be associated with the use of needles with acupuncture. ${ }^{[31,32]}$.

\section{LIMITATIONS}

The major limitation of this study is the difficulty in generalizing our final conclusion to include all UAE citizens due to our limited sample since the study was conducted within students' level at the University of Sharjah. Moreover, the ongoing cross-sectional study was completely dependent on the respondents' perception and their self-reported results which are labile to forgetfulness leading to either over- or under-estimation of the actual results.

\section{RECOMMENDATION}

An awareness campaign about Complementary and alternative medicines should be implanted to provide guidance of proper utilization and limit any possible harm resulting from misuse of CAM therapy. Another recommendation is to improve the engagement of physicians in CAM decision and further monitoring of any adverse effect that could arise during or after the CAM therapy.

\section{CONCLUSION}

The results obtained from this study indicate a high level of CAM awareness among UOS students especially the females. Moreover, students in advanced years are more knowledgeable about CAM. A positive attitude about CAM was mainly because of its claimed safety and efficacy while lack of scientific data was the predominant reason behind disbelieving. In general, the impression affected by environmental and cultural persuasion; a good example included that cupping being the most used CAM especially between local students. Despite the strong recommendations provided by WHO and DHA still, there is a large number of CAM customers ignoring those safety precautions including services received by unlicensed personnel without any medical advice. Balancing the interaction and proper patient-physician relationship is recommended for safe CAM utilization.

To sum up, CAM is considered a double-edged sword that should not be initiated before reviewing the patient's full history and medical records in collaboration with 
the patient's physician. Moreover, it is mandatory to be practiced in a licensed center by a licensed practitioner.

\section{CONFLICT OF INTEREST}

The authors declared no conflict of interest

\section{ACKNOWLEDGMENT}

The authors would like to acknowledge Dina Hamed, Ahmed Nasser, Esraa Abdelraouf for their efforts in collecting the data and writing the manuscript initial draft.

\section{REFERENCES}

1. Moquin, B., et al., Complementary and alternative medicine (CAM). Geriatric Nursing, 2009. 30(3): p. 196-203.

2. National Center for Complementary and Integrative Health. Complementary, Alternative, or Integrative Health: What's In a Name? 2016; Available at: https://nccih.nih.gov/health/integrative-health. Accessed April, 2018.

3. Therapy, A.J.o.O., Complementary and Alternative Medicine. 2011.65(6_Supplement):S31.).

4. Sampson, W., ANTISCIENCE TRENDS IN THE RISE OF THE "ALTERNATIVE MEDICINE'MOVEMENT. Annals of the New York Academy of Sciences, 1995. 775(1): p. 188197.

5. Abou El-Soud N. Herbal medicine in ancient Egypt. ; 2010.

6. Qureshi, N.A., et al., History of cupping (Hijama): a narrative review of literature. Journal of integrative medicine, 2017. 15(3): p. 172-181.

7. Ernst, E., The public's enthusiasm for complementary and alternative medicine amounts to a critique of mainstream medicine. International journal of clinical practice, 2010. 64(11): p. 1472.

8. Passalacqua, R., et al., Effects of media information on cancer patients' opinions, feelings, decision-making process and physician-patient communication. Cancer, 2004. 100(5): p. 10771084 .

9. Rossi, P., et al., Prevalence, pattern and predictors of use of complementary and alternative medicine (CAM) in migraine patients attending a headache clinic in Italy. Cephalalgia, 2005. 25(7): p. 493506.

10. Moore, J., et al., Why do people seek treatment by alternative medicine? British medical journal (Clinical research ed.), 1985. 290(6461): p. 28.

11. Harnack, L.J., S.A. Rydell, and J. Stang. Prevalence of use of herbal products by adults in the Minneapolis/St Paul, Minn, metropolitan area. in Mayo Clinic Proceedings. 2001. Elsevier.
12. Härtel, U. and E. Volger, Use and acceptance of classical natural and alternative medicine in Germany--findings of a representative populationbased survey. Forschende Komplementarmedizin und klassische Naturheilkunde $=$ Research in complementary and natural classical medicine, 2004. 11(6): p. 327-334.

13. National Cancer Institute. Complementary and Alternative Medicine. 2015; Available at: https:// www.cancer.gov/about-cancer/treatment/cam. Accessed April, 2018.

14. Rampes, H., et al., Introducing complementary medicine into the medical curriculum. Journal of the Royal Society of Medicine, 1997. 90(1): p. 1922 .

15. Giannelli, M., et al., General practitioners' knowledge and practice of complementary/ alternative medicine and its relationship with lifestyles: a population-based survey in Italy. BMC Family Practice, 2007. 8(1): p. 30.

16. Health Authority-Abu Dhabi. HAAD Standard for Scope of Practice for Traditional Complementary and Alternative Medicine (CAM) Practitioners. 2014; Available at: government.ae. Accessed April, 2018.

17. Chao, M.T. and C.M. Wade, Socioeconomic factors and women's use of complementary and alternative medicine in four racial/ethnic groups. Ethnicity \& disease, 2008. 18(1): p. 65.

18. Saydah, S.H. and M.S. Eberhardt, Use of complementary and alternative medicine among adults with chronic diseases: United States 2002. Journal of Alternative \& Complementary Medicine, 2006. 12(8): p. 805-812.

19. Elolemy, A.T. and A.M. AlBedah, Public knowledge, attitude and practice of complementary and alternative medicine in Riyadh region, Saudi Arabia. Oman medical journal, 2012. 27(1): p. 20.

20. Robinson, N., Integrated traditional Chinese medicine. Complementary therapies in clinical practice, 2006. 12(2): p. 132-140.

21. Sa'ed, H.Z., S.W. Al-Jabi, and W.M. Sweileh, Scientific publications from Arab world in leading journals of Integrative and Complementary Medicine: a bibliometric analysis. BMC complementary and alternative medicine, 2015. 15(1): p. 308.

22. Alzahrani, S.H., et al., Knowledge and attitudes towards complementary and alternative medicine among senior medical students in King Abdulaziz University, Saudi Arabia. Evidence-Based Complementary and Alternative Medicine, 2016. 2016. 
23. Akan, H., et al., Knowledge and attitudes towards complementary and alternative medicine among medical students in Turkey. BMC complementary and alternative medicine, 2012. 12(1): p. 115.

24. Loh, K.P., et al., Medical students' knowledge, perceptions, and interest in complementary and alternative medicine. The journal of alternative and complementary medicine, 2013. 19(4): p. 360366.

25. Ameade, E.P.K., et al., Medical students' knowledge and attitude towards complementary and alternative medicine-A survey in Ghana. Journal of traditional and complementary medicine, 2016. 6(3): p. 230-236.

26. Holroyd, E., et al., Beliefs and attitudes towards complementary medicine among registered nurses in Hong Kong. International Journal of Nursing Studies, 2008. 45(11): p. 1660-1666.

27. Ives, J.A. and W.B. Jonas, Energy medicine. Fundamentals of Complementary and Alternative Medicine-E-Book, 2014: p. 197.

28. Jamshed, S.Q., et al., Knowledge, perceptions, and attitudes toward complementary and alternative medicines among pharmacy students of a Malaysian Public University. Journal of pharmacy \& bioallied sciences, 2016. 8(1): p. 34.

29. Bjerså, K., E.S. Victorin, and M.F. Olsén, Knowledge about complementary, alternative and integrative medicine (CAM) among registered health care providers in Swedish surgical care: a national survey among university hospitals. BMC complementary and alternative medicine, 2012. 12(1): p. 42.

30. Mathew, E., et al., Self-reported use of complementary and alternative medicine among the health care consumers at a tertiary care center in Ajman, United Arab Emirates. Annals of medical and health sciences research, 2013. 3(2): p. 215.

31. Song, J.Y., et al., An outbreak of post-acupuncture cutaneous infection due to Mycobacterium abscessus. BMC Infectious Diseases, 2006. 6(1): p. 6.

32. Walsh, B., Control of infection in acupuncture. Acupuncture in Medicine, 2001. 19(2): p. 109. 